\title{
Under-reporting of Income and Labor Market Performance
}

\author{
Ann-Sofie Kolm*and Søren Bo Nielsen ${ }^{\dagger}$
}

June 15, 2005

\begin{abstract}
To examine the effects on labor market performance of government tax and enforcement policies, this paper develops an equilibrium model featuring tax evasion, matching frictions, and worker-firm wage bargains. In the wage bargains, workers and firms can agree on the amount of remuneration that should not be reported to the tax authorities. We find that increased taxation actually reduces unemployment, whereas more zealous enforcement has the opposite effect.
\end{abstract}

JEL codes: J64, J41, H26

Keywords: Unemployment, matching, wage bargaining, tax evasion

*Department of Economics, Stockholm University, 10691 Stockholm, Sweden. E-mail: ann-sofie.kolm@ne.su.se

${ }^{\dagger}$ Copenhagen Business School, Department of Economics, Solbjerg Plads 3, DK-2000 Frederiksberg, Denmark, E-mail: sbn.eco@cbs.dk 


\section{Introduction}

In the period June 3-13, 2004, the Danish Customs and Tax carried out a series of control operations vis-a-vis a number of firms in several service sectors. ${ }^{1}$ Most actions involved pizzerias, restaurants, and taxi companies, but a whole range of service sectors was covered. Tax evasion proved to be pervasive. For instance, among 678 pizzerias and restaurants inspected, 40 pct. had "messed-up accounts", i.e., incomplete registration of earnings. Further, of 1,846 employees in these firms, more than half were not registered, and of these no less than a third claimed to have their "first working day" in the firm, this being the reason for lacking registration of their employment. Later raids by the tax authorities confirm that under-reporting of income of workers is a wide-spread phenomenon in many service sectors, and a testimony of the importance of under-reporting is that the Ministry of Taxation in Denmark has made so-called 'Fair Play', i.e. truthful reporting of income earned and wages paid in all sectors, a top priority.

Under-reporting of income is of course not only a Danish phenomenon, but a problem for tax systems in all countries. For the tax evaders involved, under-reporting can have dire consequences. When firms refraining from paying social security taxes and from withholding income tax on behalf of their employees are detected, then the taxes due have to be paid, and on top of this both employer and employee can be fined or even imprisoned.

On a wider scale, the scope for under-reporting of income and the probability of being detected are likely to influence the working of labor markets and in particular the level of wages and the rate of unemployment. Firms and workers may agree to report only part of the remuneration of labor as official wage, paying the remainder of the remuneration as an unofficial and unreported wage component. Thereby, they save on social security taxes and personal income taxes, but face the risk of being detected with resulting fines.

This paper aims to shed light on the link between opportunities for under-

\footnotetext{
${ }^{1}$ Description of the control operations and of the sanctions associated with different forms of tax evasion is available at www.skat.dk.
} 
reporting of labor income on one hand and wage level and unemployment rate on the other. To this aim we apply a matching model of a well-defined labor market. A fixed number of workers are in the labor market, while firms enter this part of the economy, when it is profitable to do so. Firms post vacant positions, and they attempt to match with unemployed workers which have been separated from previous employment. Once they are matched, they bargain over both the official wage and over the unofficial wage. The wage bargain will take into account tax rates as well as tax enforcement policy on the part of authorities. With wages set, labor market tightness and therefore the rate of unemployment of workers are determined.

Higher taxes are normally associated with higher, or unchanged, unemployment in labor markets. In our framework we find, perhaps contrary to expectations, that a higher rate of tax, whether pay-roll or personal income tax, actually reduces unemployment. An increase in the tax rate will increase the value of tax evasion via under-reporting of income. This in turn raises the value of employment to unemployment, as evasion is open only to employed workers. The result is restrained wage demands, so that more firms will open vacancies. With the number of vacancies relative to the number of job seekers rising, unemployment falls.

Less frequent auditing of firms and workers, or lower fine rates, also reduces unemployment in our model. Since under-reporting of income again is available only to employed workers, less frequent auditing or lower punishment of evasion likewise increase the value of employment relative to unemployment. The result is restrained wage demands, and more firms will find it profitable to open vacancies. With the number of vacancies relative to the number of job seekers rising, unemployment falls.

Thus, both higher tax rates and more lenient enforcement of taxes can in principle be used in our matching framework as instruments to increase the incentives for employment and work.

We derive our results in a basic version of the model. Then we go on to show that extending the model by incorporating several formulations of unemployment benefits; separation of workers and firms upon detection of tax evasion; and taxation of company income does not alter our main insights. 
The literature on tax evasion has grown to become rather large. ${ }^{2}$ The early theoretical analyses of tax evasion are provided by Allingham and Sandmo (1972) and Srinivasan (1973), where under-reporting of income by an individual is modeled as a decision made under uncertainty. Subsequent papers have since then enhanced the basic model of individual behaviour by, for example, incorporating endogenous labour supply decisions. ${ }^{3}$ Also, general equilibrium models with tax evasion have been developed; for an example featuring commodity taxation see Cremer and Gahvari (1993).

Our paper differs from the first wave of articles on tax evasion, in that we incorporate an imperfectly functioning labour market. This facilitates an analysis of how tax and enforcement policies affect wage setting and unemployment. As the previous research takes wages to be either exogenous or determined by market clearing, such a framework will clearly not enable any examination of how involuntary unemployment is affected by tax and enforcement policies.

Moreover, one may note that the public finance approach to tax evasion issues has switched focus from the individual's decision on the extent of evasion of income tax (as in Allingham and Sandmo) towards a modeling strategy where firms under-report their true profits, sales or wages paid. This trend reflects that the institutional setting has changed. When auditing individual tax returns, tax authorities have access to reports on income paid by companies to their employees; hence, it is nearly impossible for individuals to misreport the wages and salaries paid to them. ${ }^{4}$ Our modeling strategy, where the employer and the employee together agree on the amount of income to report to the tax authorities, more closely corresponds to the institutional setting in industrialized economies today. Further, our apporach enables us to shed new light on under-reporting of labour income.

Recent years have seen some studies of underground activity in models

\footnotetext{
${ }^{2}$ See Slemrod and Yitzhaki (2002) and Schneider and Eneste (2000) for two surveys of tax avoidence and tax evasion.

${ }^{3}$ See for example Andersen (1977) and Sandmo (1981) for early contributions of endogenous labour supply and under-reporting of income.

${ }^{4}$ Even capital income is becoming intrinsically more difficult to under-report.
} 
of involuntary unemployment; see Kolm and Larsen (2001, 2003), Cavalcanti (2002), Boeri and Garibaldi (2002), and Fugazza and Jacques (2004). These papers, however, do not focus on under-reporting of income; instead, they are exclusively concerned with the activity in the underground economy.

The paper is organized as follows. Section 2 describes the basic model and examines how wages and unemployment are affected by tax evasion as well as by the tax and enforcement system. Section 3 considers some extensions of the basic model to take account of unemployment benefits; cessation of the worker-firm relationship upon detection of tax evasion; and other taxes on firms. Section 4 concludes.

\section{The Model}

The model we employ to study the relation between tax evasion and enforcement, wage formation, and unemployment is an equilibrium model of the labor market. The labour market is characterized by trading frictions due to costly and time-consuming matching of workers and firms. ${ }^{5}$

Firms file reports to the tax authorities regarding the amount of income they have paid out to their employees. This officially reported income serves as the basis for income taxes on workers and payroll taxes on firms. In addition, workers may earn income which is not reported to the tax authorities, as workers and firms are able to evade taxes by agreeing on an amount of income that goes unreported.

Tax authorities initially undertake a costless scanning of reported incomes in the economy. Unless workers and firms have spent resources in order to conceal unreported income, they will be immediately revealed as tax cheaters by the authorities. In addition, tax authorities audit a fraction of firms in the economy which are selected randomly among all firms that were not revealed as tax cheaters by the initial scanning procedure. These audits are costly, but do reveal the true compensation paid to workers. ${ }^{6}$

\footnotetext{
${ }^{5}$ The core of our model corresponds to that in the basic model in Pissarides (2000).

${ }^{6}$ See Cremer and Gahvari (1993) among others for a similar assumption of an initial scanning procedure and concealment costs.
} 
With a certain probability a worker-firm pair is targeted by an audit, after which either party has to pay a fee. No firm will choose to under-report without at the same time spending resources to conceal this, as otherwise they surely will be detected in the scanning procedure.

\subsection{Matching}

The economy consists of a large number of risk neutral individuals. Without loss of generality, we normalize this number to unity. Individuals are either employed or unemployed. Employed workers are separated from their jobs at the exogenous separation rate $s$. In our basic model we assume that if a tax-evading worker-firm pair is detected, they may nevertheless continue their relationship. ${ }^{7}$

The matching process is captured by a concave, constant-returns-to-scale matching function, $H=h(v, u)$, where $v$ is the number of vacancies supplied by firms, and $u$ is the number of unemployed workers searching for a job. As the labour force is normalized to unity, the number of unemployed workers and the number of vacancies are also the unemployment rate and the vacancy rate, respectively. The rate at which an unemployed worker finds a job is given by $H / u=h(\theta, 1)=\lambda(\theta)$, where $\theta=v / u$ captures labour market tightness. Firms fill vacancies at the rate $H / v=h(1,1 / \theta)=q(\theta)$. Consequently, we have $\lambda(\theta)=\theta q(\theta)$, where $\lambda^{\prime}(\theta)>0$ and $q^{\prime}(\theta)<0$. Higher labour market tightness $\theta$ increases workers' chance of finding a job, but reduces the likelihood of a firm finding a worker.

Equating the flows out of unemployment to the number of destroyed jobs yields the steady state unemployment rate:

$$
u=\frac{s}{s+\lambda(\theta)},
$$

which depends positively on the separation rate and negatively on tightness.

\footnotetext{
${ }^{7}$ In an extension in section 3 we consider the case where the match is dissolved upon detection of tax evasion. As will be made clear there, our results are only reinforced by assuming termination of the worker-firm relationship upon detection.
} 


\subsection{Workers and Firms}

Let $E$ and $U$ represent the expected discounted value of employment and unemployment, respectively. The values of employment in a particular firm, $i$, and unemployment can be written in the following form:

$$
\begin{aligned}
r E_{i} & =T+w_{i}^{o}(1-t)+w_{i}^{e}(1-p \delta)-C\left(w_{i}^{e}\right)-s\left(E_{i}-U\right), \\
r U & =T+\lambda(E-U)
\end{aligned}
$$

where $w^{o}$ is the officially reported wage, and $w^{e}$ is the amount of a worker's remuneration which is not reported to the tax authorities. $T$ is a lump sum transfer received by all individuals; $r$ the exogenous discount rate; $t$ the proportional income tax rate; $p$ the probability of being detected as withholding tax payments from the government; and $\delta$ the proportion of evaded income the worker has to pay as a fine if detected. ${ }^{8} C\left(w^{e}\right)$ captures concealment costs of a worker related to withholding income from tax authorities, where $C^{\prime}\left(w^{e}\right), C^{\prime \prime}\left(w^{e}\right)>0, C(0)=C^{\prime}(0)=0$. For simplicity, we assume that unemployment benefits are equal to zero initially; in section 3 we discuss the case of positive unemployment benefits.

Let $J$ and $V$ denote the expected present values of an occupied and a vacant job, respectively. The asset equations of a specific occupied job, referred to by the subscript $i$, and a vacant job, can be written as:

$$
\begin{aligned}
& r J_{i}=y-w_{i}^{o}(1+z)-w_{i}^{e}(1+p \alpha)-G\left(w_{i}^{e}\right)-s\left(J_{i}-V\right), \\
& r V=-k+q(J-V)
\end{aligned}
$$

where $y$ is worker productivity, $z$ denotes the payroll tax rate, $\alpha$ is the proportion of the evaded wage the firm has to pay as a fine if detected, and $k$ is the cost of vacancy. $G\left(w^{e}\right)$ captures the concealment costs facing a firm, where $G^{\prime}\left(w^{e}\right), G^{\prime \prime}\left(w^{e}\right)>0, G(0)=G^{\prime}(0)=0$. As will become clear, it is of no importance for the results whether concealment costs are mainly carried by the worker or by the firm.

\footnotetext{
${ }^{8}$ As the setting of our model is in continous time, $p$ is actually an intensity variable rather than a true probability level. Nevertheless, we shall often refer to $p$ as a probability, and somewhat loosely one may think of $p$ as the likelihood of detection within one time unit.
} 


\subsection{Wage Determination}

When a worker and a firm meet, they bargain over the official wage, $w^{\circ}$, as well as over the unofficial payment, $w^{e}$.

Formally we solve the wage bargaining problem by maximizing the Nash Product with respect to $w_{i}^{o}$ and $w_{i}^{e}$. The Nash Product representing a particular match, $i$, is written as $\Omega_{i}=\beta \ln \left(E_{i}-U\right)+(1-\beta) \ln \left(J_{i}-V\right)$, where $\beta$ captures workers' relative bargaining power.

In a symmetric equilibrium, $w_{i}^{o}=w^{o}$ and $w_{i}^{e}=w^{e}$, and under the assumption of free entry $V=0,{ }^{9}$ the first order conditions can be written as

$$
\begin{array}{r}
\frac{\beta}{1-\beta} \frac{1}{\phi^{\circ}} J=E-U, \\
\frac{\beta}{1-\beta} \frac{1}{\phi^{e}\left(w^{e}\right)} J=E-U,
\end{array}
$$

where $\phi^{o}=(1+z) /(1-t)$ and $\phi^{e}\left(w^{e}\right)=\left(1+p \alpha+G^{\prime}\left(w^{e}\right)\right) /\left(1-p \delta-C^{\prime}\left(w^{e}\right)\right)$ are the tax and punishment wedges. Solving for the bargained official and evaded wages, $w^{o}$ and $w^{e}$, from (6) and (7), we find that $w^{e}$ is determined by,

$$
\phi^{o}=\phi^{e}\left(w^{e}\right) .
$$

The amount of evaded income is chosen so that the tax and fine wedges are equalized. We note from (8), using the definitions of the wedges, that there is no evasion if the expected punishment rates are greater than or equal to the tax rates, or more specifically if $(1+p \alpha) /(1-p \delta) \geq(1+z) /(1-t)$. With $(1+p \alpha) /(1-p \delta)<(1+z) /(1-t)$, on the other hand, it is always optimal for the workers and the firms to agree on, at least some, evasion, $w^{e}>0$. We will concentrate on the case where there is an interior solution with tax evasion, $w^{e}>0$, and where it is not optimal for the two parties to evade all of the income, $w^{o}>0$. This implies that we specifically assume $(1+p \alpha) /(1-p \delta)<(1+z) /(1-t)$ and that the concealment cost

\footnotetext{
${ }^{9}$ An additional firm will, of course, find itself in idle position to begin with. For entry to be just (un)profitable, $V$ has to equal zero.
} 
functions are sufficiently convex. ${ }^{10}$

The condition in (8) is intuitive, since if $\phi^{o}>\phi^{e}$ the total surplus of the match can be increased by raising the amount of evaded income for a given level of total compensation. Analogously, it would be preferable for both parties to reduce the amount of tax evasion, if $\phi^{o}<\phi^{e}$.

It follows from this discussion that the amount of evaded income is in our framework affected only by parameters in the tax and enforcement system and not by labour market conditions or bargaining power. From this we can conclude the straight forward implication that:

Proposition 1 Increased taxation, i.e. an increase in $t$ or $z$, increases the amount of under-reported income, whereas a stronger enforcement, i.e. an increase in $p, \alpha$, or $\delta$, reduces the amount of under-reported income.

Proof Differentiate (8) with respect to $w^{e}, z, t, p, \alpha, \delta$.

Whereas labour market conditions and bargaining power do not have any direct impact on the amount of under-reported income, they will, however, affect the total amount of compensation for work. Given the evaded income which is determined in (8), we can derive the bargained per-period expected producer costs facing an average firm using equation (6) or (7). This yields:

$$
w^{o}(1+z)+w^{e}(1+p \alpha)+G=\beta(y+k \theta)-(1-\beta) \varphi,
$$

where $\varphi=\phi^{o} w^{e}(1-p \delta)-\phi^{o} C-w^{e}(1+p \alpha)-G \geq 0$. The parameter $\varphi$ in a sense measures the surplus associated with tax evasion; it is positive due to the properties of the concealment cost function. ${ }^{11}$

In the absence of tax evasion opportunities, the free entry condition dictates that the gross wage, $w^{o}(1+z)$, which then is total producer cost, will equal $\beta(y+\theta k)$. The sum $(y+k \theta)$ then stands for the surplus associated with a successful match between a worker and a firm. The share $\beta$ of the surplus accrues to the worker. However, when it is possible to evade taxes,

\footnotetext{
${ }^{10}$ We have assumed above that both $C($.$) and G($.$) are strictly convex functions. Strictly$ speaking, it suffices that one of them is, while the other is linear or even degenerate (equal to zero).

${ }^{11} C^{\prime}>C / w^{e}, G^{\prime}>G / w^{e}$. Hence, $\varphi=0$ only when there is no income tax evasion.
} 
doing it to the optimal extent reduces producer cost for a given tightness in line with (9). Gross cost savings due to tax evasion amount to $(1-\beta) \varphi$.

We note that a change in the amount of unreported income, $w^{e}$, has no effect on expected producer costs for given tightness. ${ }^{12}$ Hence, a marginal increase in unreported income reduces official wage demands to such extent that expected producer costs of firms are left unaffected.

\subsection{Tightness and the official wage}

Labour market tightness is derived from equations (4) and (5), using the free entry condition $V=0$, and the expression for producer costs (9):

$$
\frac{(r+s) k}{q(\theta)}=(1-\beta) y-\beta k \theta+(1-\beta) \varphi,
$$

where we recall that $\varphi$ is pinned down by parameters from the tax and punishment system as well as by the concealment cost functions; see the definition of $\varphi$ and (8). Thus (10) yields a unique solution for $\theta$.

Finally, with the unofficial wage component $w^{e}$ and tightness $\theta$ now derived, the official wage $w^{o}$ can easily be derived from the expression for user cost in (9). It is worth noting that in the absence of tax evasion opportunities, $w^{o}$ is simply given by $w^{o}=\beta(y+k \theta) /(1+z)$; with tax evasion, the official wage will naturally be reduced.

\subsection{Taxes, Enforcement, and Unemployment}

We are now ready to draw conclusions about the relationship between tax evasion and unemployment, and about the impact of tax and enforcement policies on unemployment. Starting with the relationship between tax evasion and unemployment we can conclude the following:

Proposition 2 Let the expected punishment rates be lower than the tax rates in the sense that $\phi^{\circ}>\phi^{e}(0)$. Then unemployment will fall, if workers and firms agree on tax evasion.

\footnotetext{
${ }^{12}$ Differentiating the right hand side of $(9)$ with respect to $w^{e}$ yields $\left(1-p \delta-C^{\prime}\right)\left(\phi^{o}-\right.$ $\left.\phi^{e}\left(w^{e}\right)\right)$ which is zero for the optimal choice of $w^{e}$.
} 
Proof With $(1+p \alpha) /(1-p \delta)<(1+z) /(1-t)$, firms and workers will profit from tax evasion, i.e. $w^{e}>0$ is agreed upon. No under-reporting of income, $w^{e}=0$, implies that $\varphi=0$. From (10) it follows that $\theta$ is larger when $w^{e}>0$ is agreed upon, since then $\varphi>0$. And from (1) it follows that unemployment falls with $\theta$.

The intuition is straight-forward. As under-reporting of income is available only to employed workers, enabling tax evasion in effect becomes an instrument to increase the incentive to work. The ability to evade taxes when employed increases the value of employment relative to unemployment, inducing wage moderation. Wage moderation in turn induces more firms to post vacancies, lowering unemployment.

Clearly, workers become more keen on getting access to these tax evasion opportunities the higher the tax rates are and the less severely tax evasion is controlled and punished by the government. Thus, the higher are the tax rates and the less strong is the government control of tax evasion, the more willing are workers to accept lower wages in order to avoid unemployment. That is, $\varphi$ in (9) is larger the higher are $t$ and $z$ and the lower are $p, \alpha$, and $\delta$.

As under-reporting of income is open only to employed workers, thereby serving as a side-benefit to employement, the tax evasion opportunities closely resemble the workings of various kinds of 'in work benefits'. Examples of such in-work benefits are the Earned Income Tax Credit (EITC) in the US and the Working Tax Credit (WTC) in the UK. Fringe benefits which accrue to employed workers only, induce similar outcomes, too.

The government can, of course, not directly control the amount of underreporting of income by firms and workers. But it can affect how attractive tax evasion appears by its choice of tax rates and the parameters of the enforcement system. We conclude:

Proposition 3 In case workers and firms evade taxes, $w^{e}>0$, increased taxation, i.e. an increase in $t$ or $z$, reduces unemployment whereas a stronger enforcement, i.e. an increase in $p, \alpha$, or $\delta$, raises unemployment. 
Proof Differentiating (10) yields $\partial \theta / \partial x_{1}<0$, and $\partial \theta / \partial x_{2}>0, x_{1}=$ $p, \alpha, \delta, x_{2}=t, z$. Differentiating (1) yields $\partial u / \partial x_{1}>0$, and $\partial u / \partial x_{2}<0$, $x_{1}=p, \alpha, \delta, x_{2}=t, z$.

We thus find, perhaps contrary to expectations, that higher tax rates actually reduces unemployment. The reason is that an increased tax rate will increase the value of evasion, since evasion implies escaping taxation. This in turn raises the value of employment relative to unemployment as evasion is open only to employed workers; wage demands are restrained and unemployment reduced.

This mechanism becomes even more clear, if we consider the impact of taxes on unemployment in the absence of opportunities to under-report labour income. In the absence of under-reporting of income, this model collapses to the basic Pissarides model (Pissarides (2000)), where an increase in, for example, the payroll tax rate induces wage adjustment which leaves producer costs and unemployment unaffected in equilibrium. When the payroll tax rate increases, firms will open less vacancies as expected profits falls. However, as less vacancies are opened it becomes more difficult to get a new job in case of job loss, and in order to avoid unemployment, wages are restrained. In case of no unemployment benefits or of benefits indexed to the consumer wage, wages are restrained to such extent that the producer wage and thus unemployment is unaffected in equilibrium.

These mechanisms are also present if we allow for under-reporting of labour income. However, in the presence of under-reporting there is an additional effect which induces wage demands to fall further. When the payroll tax rate increases, it becomes more valuable to under-report income, and thus more valuable to be employed and have access to these tax evasion opportunities. Accordingly, workers become more willing to accept lower wages in order to avoid unemployment.

For analogous reasons, punishing tax evasion through more frequent auditing or higher fines reduces the attractiveness of tax evasion. As a consequence, wage demands increase, and less firms will open vacancies; unemployment rises. Workers are simply less willing to accept low wages as opposed to unemployment. Conversely, reducing the punishment of tax evasion can 
actually function as an instrument to increase the incentive to work; restrain wage demands and reduce unemployment.

Introducing the government budget restriction enables us to take a closer look at the content of proposition 2. The government budget restriction in per-capita form is given by:

$$
T=(1-u)\left[w^{o}(t+z)+w^{e} p(\alpha+\delta)\right]-F(p(1-u)) .
$$

The right hand side has the net revenue of the government, i.e. the excess of revenue from taxation and auditing over the cost of auditing, $F(p(1-u))$. The cost of auditing is written as a function of the number of firm-worker relationships inspected. On the left hand side is the resulting lump-sum transfer $T$ paid to all workers.

Appropriate adjustments in $T$ clearly enable the policy changes in proposition 2 to be fully financed. Alternatively, it is possible to keep $T$ unchanged in a reform by combining a reduced audit rate or reduced fines with higher tax rates; such a reform leads to a double reduction in unemployment. ${ }^{13}$

\subsection{An alternative formulation of fines}

Our remark above that one would expect the fines $\alpha$ and $\delta$ to be balanced against punishment of other crimes suggests an alternative formulation of these fines. In practice, fines often consist of both the tax that the worker or employer attempted to evade in the first instance, and a genuine fine normally expressed as a certain percentage of the tax. ${ }^{14}$

Hence, a possible alternative formulation of fine parameters could be

$$
\delta=a t, \quad \alpha=a z
$$

\footnotetext{
${ }^{13}$ Taking as given that we are located on the positively sloped side of the Laffer curve in the sence that an increase in $t, z, \alpha, \delta$ or $p$ does generate higher revenue.

${ }^{14}$ Andreoni et al. (1998, p. 820) write, for example, that civil penalties typically are applied at a rate of 20 percent of the portion of the underpayment of tax resulting from a specified misconduct; in cases of fraud, a civil penalty may be applied at a rate of 75 percent. In Denmark, tax evasion or cheating is often punished with a payment equal to 200 pct. or more of the tax that originally was avoided, the relevant percentage being determined by the amount of tax evaded.
} 
where $a$ would be somewhere between, say, 1 and 3, so that both the original tax and a fine proportional to the tax would be included in the fine payment to authorities. The parameter $a$ would be regarded as fixed, whereas the fine payment - contrary to our formulation above - would vary with changes in tax rates. Relative to the comparative statics analysis above, there would be no change in the analysis of altering the auditing probability, $p$. But a change in either of the two taxes $t$ or $z$ would give rise to additional terms, as payments upon detection would change in line with the relevant tax rate.

It turns out that as long as the expression $1-p a-C / w^{e}$ can be taken as positive, the qualitative results concerning the effects of tax increases on market tightness and unemployment will be the same as above. While a positive sign of the expression seems natural, it is not a necessity, though.

In the next section we shall revert to original and simpler formulation of fines.

\section{Extensions}

In this section we look at the implications of several modifications and extensions to our framework. In turn, we consider the existence of positive unemployment benefits; the possibility of separation of workers and firms upon detection; and other taxes on firms such as the corporate income tax.

\subsection{Positive Benefits}

We first explore the consequences of having positive unemployment benefits. The basic model featured only a common transfer to both employed and unemployed individuals and no special benefits to the unemployed. Introducing unemployment benefits implies facing questions as to how these benefits are determined, and a couple of options are explored below.

The value function for an unemployed worker is now written:

$$
r U_{i}=T+B+\lambda\left(E_{i}-U_{i}\right)
$$


where $B$ denotes the after-tax benefit received when unemployed. The value functions for employed workers and firms are still given by (2), (4), and (5).

Accounting for benefits will not influence the first order conditions determining wages, (6) and (7), with the exception that the term $E-U$ becomes $E-U=\frac{1}{r+s+\lambda}\left(w^{o}(1-t)+w^{e}(1-p \delta)-C\left(w^{e}\right)-B\right)$. Hence, (8) still pins down the size of unreported income as given by concealment cost functions and the tax and punishment system. Changes in the unemployment benefit system will thus not influence the amount of unreported income.

We explore two natural candidates for the definition of unemployment benefits. First, we assume that the pre-tax benefit is indexed to the average (official) wage, i.e., $B /(1-t)=\rho w^{o}$, implying an official constant replacement rate. Second, we assume that the pre-tax unemployment benefit is fixed at $\bar{B}$, so that the after-tax benefit can be written $B=\bar{B}(1-t) .{ }^{15}$

\section{Constant replacement rate}

Proceeding with the first definition we can derive the per-period expected producer costs from (6), keeping in mind that (8) determines the unreported income, $w^{e}$. This yields:

$$
w^{o}(1+z)+w^{e}(1+p \alpha)+G=\frac{1}{1-\rho(1-\beta)}\left[\beta(y+k \theta)-(1-\beta) \varphi^{\prime}\right],
$$

where $\varphi^{\prime}=\phi^{o} w^{e}(1-p \delta)-\phi^{o} C-(1-\rho)\left(w^{e}(1+p \alpha)+G\right) \geq 0$. Comparing (13) with (9) allows to clarify how positive benefits indexed to the (official) wage affects producer costs and thereby unemployment.

First, we note that the square brackets on the right hand side is multiplied by $1 /(1-\rho(1-\beta))$. This has no impact on the qualitative results derived from the basic model. ${ }^{16}$ Secondly, and more interesting, we note that $\rho$

\footnotetext{
${ }^{15}$ Note that in both cases unemployment benefits are - realistically - assumed to be subject to personal income taxation. Alternatively, unemployment benefits might be exempt from tax.

${ }^{16}$ This term only amplifies the effect from comparative statics as $1 /(1-\rho(1-\beta))>1$. An increase in for example $y$ increases wage demands as the workers want to reap a fraction of the productivity increase. With benefits indexed to the average (official) wage, they rise with the higher official wages. As benefits increase, official wage demands are increased further. Thus, the effect on wages is amplified. Analogous reasoning holds for a change in $p, \alpha$, or $\delta$ and $t$ or $z$.
} 
enters the expression for $\varphi^{\prime}$. This implies, in contrast to the basic model, that the expected producer costs are affected by changes in the amount of unreported income, $w^{e}$. Specifically, we have $\frac{\partial \varphi^{\prime}}{\partial w^{e}}=\phi^{o}\left(1-p \delta-C^{\prime}\right) \rho>0$ for $\rho>0$. In the basic model with no unemployment benefits, i.e., $\rho=0$, an increase in unreported income reduced official wage demands such that expected producer costs were unaffected. With positive benefits, $\rho>0$, an increase in unreported income will induce official wage demands to fall to such an extent that total expected producer costs actually fall. The reason is that the reduced official wage demands also lower unemployment benefits. This reduction in unemployment benefits induces wage moderation which causes total expected producer costs to fall.

We know from proposition 3 that unemployment falls following an increase in $t$ or $z$ or a reduction in $p, \alpha$, or $\delta$. In the presence of positive unemployments benefits, unemployment falls for a second reason, since it becomes optimal to under-report more income. As this causes unemployment benefits to fall, in turn inducing wage moderation, unemployment drops. Accordingly, benefits indexed to the (official) wage reinforces the effect on unemployment of a change in $p, \alpha$ or $\delta$ and $z$ or $t$. This insight is summarized in the following proposition:

Proposition 4 With unemployment benefits indexed to the official wage, $B=\rho w^{o}(1-t)$, and workers and firms evading taxes, $w^{e}>0$, an increase in $t$ or $z$, or a reduction in $p, \alpha$, or $\delta$, will induce an additional wage moderating effect, as unemployment benefits fall when workers and firms increase the unofficial wage. This additional mechanism will also work to reduce unemployment.

Proof Differentiating (13) with respect to the producer costs and $w^{e}$ yields $\partial\left(w^{o}(1+z)+w^{e}(1+p \alpha)+G\right) / \partial w^{e}<0$. Differentiating (10) yields $\partial \theta / \partial w^{e}>0$. Finally, differentiating (1) yields $\partial u / \partial w^{e}=\partial u / \partial \theta \cdot \partial \theta / \partial w^{e}<0$.

Fixed pre-tax benefits

Now let benefits be fixed pre-tax, i.e., $B=\bar{B}(1-t)$, where $\bar{B}$ is the pretax unemployment benefit. The per-period expected producer costs derived 
from (6) then take the form:

$$
w^{o}(1+z)+w^{e}(1+p \alpha)+G=\beta(y+k \theta)+(1-\beta) \bar{B}(1+z)-(1-\beta) \varphi,
$$

where again $w^{e}$ is determined in (8). This expression reveals that changes in $\alpha, \delta$ and $t$ will work through the same channels as in the basic model.

However, there will be a direct effect on producer costs of a change in the payroll tax rate, $z$. An increase in $z$ will have a direct positive effect on producer costs, which goes in the opposite direction to the effect of $z$ through $\varphi$ (see proposition 2). This direct positive effect on producer costs is the standard effect found in models of equilibrium unemployment when benefits are not indexed to the wage (see Pissarides (1998)). ${ }^{17}$ This implies that an increase in $z$ will have an ambiguous effect on unemployment in contrast to the basic model (where $B=0$ ) or in contrast to the model where benefits are indexed to the official wage $\left(B=\rho w^{o}(1-t)\right)$.

Proposition 2 holds for the same reason as in the basic model, when positive unemployment benefits are accounted for (irrespective of the definition of unemployment benefits).

\subsection{Separation upon detection}

This section explores the consequences of having jobs dissolved upon detection of tax evasion. The basic model in section 2 implied that the worker-firm

\footnotetext{
${ }^{17}$ It is interesting to note the incidence of the payroll tax and how it varies with the definition of unemployment benefits: When there is an increase in the payroll tax, the producer wage initially increases. However, as firms will open less vacancies when wage costs are higher, tightness falls. This reduction in tightness will induce wage moderation, which in turn reduces wage costs and induces tightness to increase again. Thus the burden of the payroll tax is also carried by the worker. When benefits are indexed to wages, benefits will fall as wages are moderated. And as benefits fall, wages are moderated further. In fact, with benefits being indexed to the wage, the worker will carry the full burden of the tax, leaving producer cost unaffected in equilibrium. However, in the absence of this indexation of benefits, the burden of the payroll tax rate is shared by both the worker and the firm, which causes producer costs to increase in this case.
} 
relationship would continue even in the situation where their common evasion of taxes was detected. The alternative hypothesis is that the relationship is terminated on account of such detection of tax evasion.

With separation upon detection, the value functions for an employed worker and a filled vacancy are written:

$$
\begin{gathered}
r E_{i}=T+w_{i}^{o}(1-t)+w_{i}^{e}(1-p \delta)-C\left(w_{i}^{e}\right)-(s+p)\left(E_{i}-U\right), \\
r J_{i}=y-w_{i}^{o}(1+z)-w_{i}^{e}(1+p \alpha)-G\left(w_{i}^{e}\right)-(s+p)\left(J_{i}-V\right),
\end{gathered}
$$

where $s+p$ now captures the effective separation rate. ${ }^{18}$ The value functions for unemployed workers and vacancies are still given by (3) and (5).

Having jobs separated upon detection will not influence wage bargains. The evaded wage and the expected producer costs are thus still given by (8) and (9). Changes in the audit rate, $p$, will affect the expected producer costs through its impact on the expected punishment rates (working through $\varphi$ ) as was described in the basic model. However, changes in $p$ will now also have a direct effect on tightness and unemployment.

The equation determining tightness is given by:

$$
\frac{(r+s+p) k}{q(\theta)}=(1-\beta) y-\beta k \theta+(1-\beta) \varphi,
$$

where it follows that an increase in $p$ reduces tightness directly by reducing the expected job duration. As jobs on average last a shorter time when matches are dissolved upon detection, less firms will open vacancies. Consequently, an increase in $p$ induces tightness to fall, both because the expected producer costs increase and because the expected job duration falls.

Equating the flows out of unemployment to the number of destroyed jobs yields the steady state unemployment rate:

$$
u=\frac{s+p}{s+p+\lambda(\theta)}
$$

where an increase in $p$ now has a direct impact on unemployment in addition to the effect working through tightness. An increase in $p$ increases unemployment directly simply by increasing the rate of separations. In addition,

\footnotetext{
${ }^{18}$ Again, although we loosely speak of $p$ as the probability of detection, it really stands for the intensity of auditing rather than a likelihood.
} 
an increase in $p$ reduces the profitability of opening vacancies both because expected producer costs increase and because jobs on average last a shorter time. As less vacancies are opened, the transition rate into employment falls. Thus, unemployment increases following an increase in the audit rate both because the transition rate into employment falls and because the transition rate out of employment increases. All in all, separation upon detection reinforces the effect on unemployment of a change in the audit rate, $p$.

The results in proposition 3 regarding the audit rate are consequently reinforced by having matches dissolved upon detection. Changes in $\alpha$ or $\delta$ and $z$ or $t$ will work through the same channels as in the basic model (see proposition 3)

\subsection{Including firm income taxes}

Until now, we have exclusively focused on taxation of labor income in a setting in which both firms and workers are liable to pay tax on labor. In reality, of course, firms pay other taxes. Most of the other taxes paid and subsidies received by firms we can safely ignore here, but there is one good reason for taking a brief look at the taxation of firm income (such as by means of the corporate income tax). This is the fact that when a firm agrees with a worker to have part of the remuneration of labor be paid out as unofficial wage, then this part cannot be deducted from the firm's revenue in computing its taxable income. So while the firm may gain from avoiding pay-roll taxation, ceteris paribus it will lose by experiencing an increase in its taxable income, leading to a higher company tax. This effect can be avoided, if in addition to evasion of pay-roll taxation the firm can also evade income taxation through under-reporting of revenues.

Against these observations we now extend our framework to incorporate income taxation of the firm and a mechanism for evading this tax, too. To begin with, only the firm side of the model is affected.

We use the following notation. $y$ still denotes true revenue of the firm, while $y^{o}$ is the official part of it, as appearing on the firm's tax return. The company income tax is levied at the rate $x$, and pay-roll tax as well 
as the official wage can be deducted from the income tax base. Declared taxable income thus is $y^{o}-w^{o}(1+z)$, while true taxable income instead is $y-w^{o}(1+z)-w^{e}(1+z)$.

The difference between true and official taxable income hence is $y-y^{o}-$ $w^{e}(1+z)$. From this expression we easily see that paying out unofficial income directly entails an increase in taxable income of $w^{e}(1+z)$, and that a lower value of official $\left(y^{o}\right)$ than true $(y)$ revenue brings down taxable income.

We assume that the firm has an opportunity, coming at a cost, to evade income tax, and that such evasion is detected at the same probability as evasion of pay-roll or labor income taxation. In other words, if and only if a firm-worker pair is inspected will authorities learn about both company income and wage tax evasion. We also assume that fines as well as costs of evasion are a function of evaded income, or $y-y^{o}-w^{e}(1+z)$. That is, given that the firm already evades pay-roll tax and pays out an unofficial wage component, it can for free reduce its income by the amount $w^{e}(1+z)$ (i.e. without incurring fines or costs of evasion). ${ }^{19}$

It is clear by now that the firm's decision as to official revenue hinges on the size of the unofficial wage it pays to the worker. Vice versa, the willingness of the firm to pay out unofficial and official wage components might depend on the size of the official revenue on its income tax return. How these interdependencies work themselves out is determined by the timing of the decisions on the part of the firm. Here, we shall assume that the firm first engages in bargaining with its worker about official and unofficial wage components, and second, it fills out its income tax return.

At the point where the firm computes its official taxable income, $w^{\circ}$ and $w^{e}$ are then already given. With a fine of $\xi$ per unit of income evaded from

\footnotetext{
${ }^{19}$ An example may clarify this. Suppose the firm pays 40 in official wage and likewise 40 in unofficial wage. The payroll tax is 25 pct. With these numbers, paying 40 in unofficial rather than official wage implies that the deduction for wages in the firm's income statement is reduced by 50 . If its true revenue is 300 , then declaring an official revenue of 250 will imply no evasion of income tax, as the official income of 200 (250-50) corresponds to true income (300-100). On the other hand, if the firm only declares a revenue of 200 , then evaded income amounts to 50 , and if detected the firm will have to pay a fine accordingly.
} 
tax and a cost of evasion of $H\left(y-y^{o}-w^{e}(1+z)\right)$ where $H^{\prime}(),. H^{\prime \prime}()>$. (for positive arguments of the functions), $H(0)=H^{\prime}(0)=0$, the income of the firm net of taxes, expected fines, and costs of evasion can be written as

$$
\begin{aligned}
& {\left[y-\left(w^{o}+w^{e}\right)(1+z)\right](1-x)+w^{e} z-p \alpha w^{e}-G\left(w^{e}\right)} \\
& +x\left(y-y^{o}-w^{e}(1+z)\right)-p \xi\left(y-y^{o}-w^{e}(1+z)\right)-H\left(y-y^{o}-w^{e}(1+z)\right) .
\end{aligned}
$$

The first term denotes its true net of tax income in the absence of all tax evasion. The next three terms stands for tax savings, expected fines and costs of evasion associated with pay-roll tax, while the final three terms are the parallel items for the company income tax.

Deciding on the optimum amount of income tax evasion is then tantamount to finding the $y^{o}$ which maximizes the net value of the latter three terms. The first order condition yields

$$
x=p \xi+H^{\prime}\left(y-y^{o}-w^{e}(1+z)\right) .
$$

The marginal tax saving has to equal the sum of the marginal expected fine and the marginal cost of evasion. An interior solution with $y-y^{o}-w^{e}(1+z)>$ 0 is guaranteed with $x>p \xi$, which we assume holds. This expression nails down the amount of income tax evasion as

$$
y-y^{o}-w^{e}(1+z)=\left(H^{\prime}\right)^{-1}(x-p \xi)
$$

or the amount of official revenue as in,

$$
\left.y^{o}=y-w^{e}(1+z)\right)-\left(H^{\prime}\right)^{-1}(x-p \xi) .
$$

The greater is the unofficial wage or the pay-roll tax, the lower is declared revenue. Moreover, the higher is the income tax rate, and the lower is the likelihood of detection, the lower is declared revenue.

The most important relationship here is the first one, i.e. between the unofficial wage component and declared income and thus net income. Utilizing income tax evasion opportunities and properly compensating in declared income for unofficial wage payments, the firm on net reduces its taxable income by

$$
x\left(y-y^{o}-w^{e}(1+z)\right)-p \xi\left(y-y^{o}-w^{e}(1+z)\right)-H\left(y-y^{o}-w^{e}(1+z)\right)
$$




$$
=(x-p \xi)\left(H^{\prime}\right)^{-1}(x-p \xi)-H\left(\left(H^{\prime}\right)^{-1}(x-p \xi)\right) \equiv K(x-p \xi) .
$$

In this expression, $K(x-p \xi)$ stands for the net gains from exploiting income tax evasion opportunities. The term $K(x-p \xi)$ is the income tax evasion counterpart to the wage tax evasion term $\varphi$ in the basic model, and $K($.$) is$ positive due to the properties of the concealment cost function. ${ }^{20}$

With this information we can now turn to wage bargaining. The flow equation for an active firm is

$r J_{i}=\left[y-\left(w_{i}^{o}+w_{i}^{e}\right)(1+z)\right](1-x)+w_{i}^{e} z-p \alpha w_{i}^{e}-G\left(w_{i}^{e}\right)+K(x-p \xi)-s\left(J_{i}-V\right)$.

Compared to the basic model, the equation takes into account that the firm pays income tax, but can profit from evasion of same tax. The flow equation for vacancies is still (5).

Going through the same steps as in section 2 we can derive new versions of equations (6) and (7) which nail down the official and the unofficial wage. We find that $w^{e}$ is implicitly determined by:

$$
\frac{(1+z)(1-x)}{1-t}=\frac{1-x(1+z)+p \alpha+G^{\prime}\left(w^{e}\right)}{1-p \delta-C^{\prime}\left(w^{e}\right)}
$$

where the left hand side is the slightly modified official tax wedge, $\tilde{\phi}^{o}$, and the right hand side is the slightly modified punishment wedge, $\tilde{\phi}^{e}$. The numerators on both sides of the equation contain the common term $-x(1+z)$ featuring the company income tax rate $x$. The interesting question is whether taking account of firm income taxation will raise or lower the amount of wage which is not declared to authorities. It turns out that both directions are possibilities. To see this, partially differentiate $\tilde{\phi}^{o}-\tilde{\phi}^{e}=0$ in (21) with respect to $x$ and $w^{e}$. The result is

Proposition 5 The unofficial wage component $w^{e}$ increases (decreases, stays constant) upon the introduction of the company income tax, if $z-p \alpha-G^{\prime}\left(w^{e}\right)$ in the no-company-tax situation is positive (negative, zero).

\footnotetext{
${ }^{20} H^{\prime}>H /\left(y-y^{o}-w^{e}(1+z)\right) . K(x-p \xi)=0$ only when there is no income tax evasion, i.e., when $x-p \xi \leq 0$.
} 
Proof Differentiate (21) with respect to $w^{e}$ and $x$.

Going back to section 2, the condition in the proposition is equivalent to the numerator of $\phi^{o}$ being greater than the numerator of $\phi^{e}\left(w^{e}\right)$. (The two tax factors have to be equal, but their numerators can have any relationship.) In a loose sense, $z-p \alpha-G^{\prime}\left(w^{e}\right)$ being positive implies that it is relatively more attractive for the firm than for the worker to evade labor tax. Accordingly, if the firm is a more effective tax evader than is the worker, then introducing company income taxation leads to more extensive evasion of wage taxation.

The proposition connects wage tax evasion to company taxation. Similarly, it is possible to relate total labor costs, tightness and unemployment to the company tax and also to the opportunities to evade this tax. Similar steps as those leading to equation (9) can be used to derive total producer costs. $^{21}$ Using the expression for total producer costs and (20) and (5) under the assumption of free entry, we can write the equation determining tightness as

$$
\frac{(r+s) k}{q(\theta)}=(1-\beta) y(1-x)-\beta k \theta+(1-\beta)(K(x-p \xi)+\tilde{\varphi}) .
$$

where $\tilde{\varphi}=\tilde{\phi}^{o} w^{e}(1-p \delta)-\tilde{\phi}^{o} C-w^{e}(1+p \alpha)-G+w^{e}(1+z) x \geq 0$. $\tilde{\varphi}$ is positive due to the properties of the concealment cost functions and $\partial \tilde{\varphi} / \partial w^{e}=0$ due to the envolope property as discussed in the basic model. Unemployment is still given by (1).

The company income tax affects tightness and thereby unemployment in three different ways. First, as a direct consequence of the tax, firm profits fall which reduces tightness and increases unemployment. Second, an increased taxation of company income increases the net gain of income tax evasion which instead induces more firms to enter the market. This tends to increase tightness and reduce unemployment. However, obviously the former effect must dominate this latter effect, as the gain from evading income tax can never exceed taxation of the firm's revenue. Third, the tax rate affects the gains that can be made by evading wage payments. An increase in $x$ reduces

\footnotetext{
${ }^{21}$ Total producer costs are given by $w^{o}(1+z)(1-x)+w^{e}(1+p \alpha-(1+z) x)+G=$ $\beta(y+k \theta)(1-x)+\beta K(x-p \xi)-(1-\beta) \tilde{\varphi}$.
} 
the tax and punishment wedges, which reduces the gains from wage tax evasion. This effect thus increases wage demands which reduces tightness and employment. We can thus conclude that

Proposition 6 An increase in the company income tax rate reduces tightness and increases unemployment.

Proof Differentiating (22) yields $\partial \theta / \partial x<0$. Differentiating (1) yields $\partial u / \partial x>0$.

An alternative to the analysis above is to assume that when the firm is inactive, it can deduct the vacancy cost $k$ from the income tax, or rather enjoy a tax rebate of $x k$. To take this into account we write the flow equation for an inactive firm as $r V=-k(1-x)+q(J-V)$. Two additional effects on tightness and unemployment of a higher income tax rate emerge. First, an increase in $x$ reduces the per period vacancy cost which induces more firms to enter. Second, an increase in $x$ reduces the surplus of the match due to saved vacancy costs. This causes wage moderation and more firms to enter. Both effects increase tightness and reduce unemployment, thus working in the opposite direction to the effects in proposition 6 .

It is straightforward to verify that propositions 1 to 3 hold even in the presence of a company income tax. This can be shown proceeding along the lines of the proofs of the three propositions. Accordingly, lighter taxation of labor or stronger tax enforcement will raise unemployment, even if firms also pay tax on company income. Interestingly, an increase in $p$ will now have an additional negative impact on tightness and employment. The reason is that an increase in $p$ also punishes firms by making company income tax evasion less attractive. Recall that any income tax evasion by firms is detected along with the evasion of labour taxes. This will have a direct negative effect on the attractiveness for firms to enter which consequently reduces tightness and thereby increases unemployment. 


\section{Conclusions}

Much of tax evasion in modern-day industrialized countries, especially within certain service sectors, takes the form of firms and workers agreeing on underreporting the wages paid to workers. This way, firms save on payroll taxes and workers save on personal income taxes. Suspecting such under-reporting of wages, tax authorities may decide to audit firms closely, and if they detect irregularities they can impose fines on at least one of the two parties. The interesting question then is how the scope for tax evasion through underreporting of wages will affect the remuneration of workers, producer costs, and the performance of the labor market.

In this paper we have set up a labor market model exactly to asses the effects of tax rates and enforcement of taxation on the level of wages and the rate of unemployment. We found that tighter auditing on the part of authorities would lead to higher producer costs and more unemployment. Conversely, and perhaps somewhat surprisingly, we at the same time derived that higher wage taxes (on payrolls or personal incomes) would lead to lower unemployment. The main mechanism responsible for this result is that higher tax rates make tax evasion more attractive and rewarding. And as evasion is available only to employed workers, higher wage taxes increases the value of having a job which restrains wage demands.

Our examination of several extensions of the basic model revealed that the main results concerning the relationship between tax rates and enforcement parameters on one hand and unemployment and labor costs on the other, carry over to different settings, where detection of tax evasion leads to the cessation of the worker-firm relationship; where unemployed workers receive unemployment benefits; or where firms in addition to payroll taxes pay regular income taxes.

The framework we have set up can be fruitfully applied to study further questions related to taxation and enforcement of taxation. One interesting issue, already touched upon in the paper, is the incidence of taxes, enforcement, and social security transfers in the labor market, i.e. the degree to which the worker (firm) carries the burden of higher taxes, more stringent 
enforcement, or cuts in unemployment insurance. Another topic is the welfare consequences of enhanced use of tax and enforcement instruments. A study of this latter topic will be complicated by the fact that inefficiences related to resource use in inspections or behavioral distortions may interfere with search inefficiencies inherent in a labor market characterized by frictions in the matching of workers and firms. Nevertheless, we plan to investigate these issues in future work.

\section{References}

[1] Andersen P., 1977, Scandinavian Journal of Economics 79, 375-83.

[2] Andreoni, J., B. Erard, and J. Feinstein, 1998, Journal of Economic Literature 36, 2, pp. 818-860.

[3] Allingham, M.. G. and Sandmo, A., 1972, Income tax evasion: A theoretical analysis, Journal of Public Economics 1, 323-338.

[4] Boeri, T., and P. Garibaldi, (2002) "Shadow activity and unemployment in a depressed labor market", CEPR Discussion paper, DP3433.

[5] Cremer, H., and F. Gahvari, 1993, Tax evasion and optimal commodity taxation, Journal of Public Economics 50, 261-275.

[6] Cremer, H., and F. Gahvari, 1994, Tax evasion, concealment and the optimal linear income tax, Scandinavian Journal of Economics 96(2), 219-239.

[7] Cavalcanti, T., 2002, Labor Market Policies and Informal Markets", Working Paper, Universidade Nova de Lisboa.

[8] Daveri, F. and G. Tabellini, 2000, Unemployment, Growth and Taxation in Industrial Countries, Economic Policy 30, 47-88.

[9] Fugazza, M. and J-F Jacques, 2004, Labour Market Institutions, Taxation and the Underground Economy, forthcoming in Journal of Public Economics. 
[10] Kolm, A-S., and B. Larsen, 2001, Wages, Unemployment, and the Underground Economy, Working paper 2001:8, Department of Economics, Uppsala University, forthcoming in Taxation and Labour Market Performance, Eds. J. Agell and P.B. Sorensen, MIT press.

[11] Kolm, A-S and B. Larsen, 2003 Does Tax Evasion Affect Unemployment and Educational Choice?, Working Paper 12-2003, Department of Economics, Copenhagen Business School.

[12] Pissarides, C., 1998, The Impact of Employment Tax Cuts on Unemployment and Wages: The Role of Unemployment Benefits and Tax Structure, European Economic Review 42, 155-183.

[13] Pissarides, C., 2000, Equilibrium Search Theory. Cambridge: MIT Press.

[14] Slemrod, J., and S. Yitzhaki, 2002 Tax Avoidence, Evasion, and Administration, Handbook of Public Economics Vol.3, eds. A.J. Auerbach and F. Feldstein, (North- Holland).

[15] Schneider, F., and D. Eneste, 2000 Shadow Economies: Size, Causes, and Consequences, Journal of Economic Literature, 38, 77-114.

[16] Yitzhaki, S., 1974 A Note on 'Income Tax Evasion: A Theoretical Analysis', Journal of Public Economics, Vol. 3, No. 2, 475-480.

[17] Siesto, V., 1992: Concepts and methods involved in the last revision of Italy's GDP. Guidebook to Statistics on the hidden Economy. Conference on European Statisticians, Economic Comission for Europe, United Nations, New York.

[18] Sandmo, A., 1981, Income Tax Evasion, Labour Supply, and the Equityefficiency Trade-off, Journal of Public Economics 16, 265-88.

[19] Srinivasan ,T.N.,1973, Tax Evasion, A Model, Journal of Public Economics 2, 339-346. 